\title{
Homenagem ao Professor Tuiskon Dick
}

\section{Ludwig Buckup}

Quando a Dra.Claudia Lima Marques me telefonou, no início desta semana, pedindome que assumisse a tarefa, certamente honrosa, de preparar uma apresentação formal do principal homenageado deste certame -.. o Prof. Tuiskon Dick - confesso que, num primeiro momento, pensei em fugir do encargo. $O$ tempo eta pouco para o recolhimento de todos aqueles dados biográficos imprescindíveis para momentos como este, havia um enorme volume de fatos e circunstâncias a serem considerados e selecionados e restava a minha própria insegurança sobre a minha capacidade de levar ao público urn retrato que faça realmente justiça ao luminoso caminho percorrido pelo eminente colega. Mas afinal, a força dos laços de amizade e de admiração criados e solidificados em meio século de convivência pessoal e acadêmica falaram mais alto, deixando-me com a esperança de que os meus ouvintes haverão de perdoar alguma falta, alguma omissão, algum nome, alguma data esquecidos. Mais do que isto, lancei-me ao desafio cobrado pela colega Dra. Claudia para, quem sabe, integrar-me mais uma vez ao movimento de resgate e preservação do ideal da internacionalização da universidade brasileira, que hoje aqui se comemora e que sempre foi o ideal maior do educador universitário Tuiskon Dick. Mas o maior estimulo recebido e rotalmente irrecusável, veio dos amigos Abilio Baeta Neves e Gerhard Jacob, que são os maiores especialistas em Tưskon Dick, em Dick-ismo e na mais complexa disciplina da sociologia acadêmica - a Dickologia, em nosso meio.

Falar aqui apenas de uma cronologia biográfica cettamente não corresponde às expectativas dos promotores deste evento. A té porque a exposição pública de Dick, seja no meio univetsitário, seja na administração da educação superior brasileira, fez do homenageado uma das figuras mais conhecidas e respeitadas no Brasil. Assim, prefiro tentar interpretar os caminhos escolhidos e percorridos, suas posições perante os desafios da ciência e principalmente, o perfil humano do homem educador e gestor na vida acadêmica brasileira.

A minha geração acadêmica, então fotmandos da biologia, da química e da física, foi literalmente atropelada pela compctência didática e pedagógica do Prof. Dick em. 1955, portanto há exatamente meio século, no auditório da Faculdade de Filosofia. Ninguém 
esqueceu o seu desempenho no histórico Curso de Extensão Universitátia sobre "Os Fundamentos Bioquímicos do Metabolismo", que teuniu centenas de ouvintes extasiados diante do novo mundo da Bioquímica modema que pela primeira vez se abria de forma competente em nosso meio.

Já graduado em Química (1945 e 1946), mestre em Bioquímica pela University of IIIinois (1951), e ptofessor-assistente e catedrático interino de Química Orgânica e Biológica na então URGS, Dick recebera de seu mestre e inspirador Bernardo Geisel a ordem de estudar biologia, visando colocar a Bioquímica em nosso espaço universitário. Féz mais, cursou a Medicina inteira, ao lado de sua irmã Gudrun Dick Algöwer, apenas para prepararse melhor para a tarefa que o Prof. Geisel reservara para ele. E os resultados estão aí. A UFRGS tem hoje um dos mais conceituados departamentos de bioquímica do Brasil e um prograna de pós-graduação que ostenta o grau mais alto na avaliação da CAPES, cuja criação e organização levam a matca indiscutivel do nosso homenageado. Completou sua obra com duas carreiras paralelas nas cátedras de Química Fisiológica e na de Quínica Orgânica e Biológica.

A vocação para o magistério certamente foi-lhe colocada no berço pelo seu ilustre pai, o Prof. Theobaldo Dick, em Lajeado, no dia de seu nascimento em seis de março de 1927.

O Professor Theobaldo, então diretor do Colégio Lajeadense, depois denominado Colégio Evangélico Alberto Torres, exerceu profunda influência não apenas sobre seus filhos, mas também sobre muitos jovens lajeadenses que depois se destacaram na vida pública sulriograndense e que recordam o seu nome com enorme respeito. De sua casa, Tuiskon Dick trouxe bern mais do que as primeiras letras - trouxe a tígida disciplina pessoal tão cara aos descendentes dos imigrantes, a sensibilidade para as questões sociais e principalmente, a cultura geral. Ėm sua casa se lia e se lia muito. O pai Theobaldo, como conta o próprio filho, possuía em sua biblioteca "O Capital" de Karl Marx e que tinha lido realmente por inteiro. Não surpreende portanto que cra comum encontrarmos Tuiskon Dick no famoso apartamento que ocupava com Abílio Baeta Neves em Brasilia, altas horas da noite, ouvindo as sonatas solo para violino ou os Concertos Brandenburgueses de Johann Sebastian Bach, enquanto lia uma biografia de Albert Schweizer ou a correspondência trocada entre Hans Sachs e Albrecht Dürer. E o que ainda faltava - - talvez a consagrada sensibilidade espiritual lutetana - foi buscar no Colégio Sinodal, no "Spiegelberg" em São Leopoldo, de onde saiu para a universidade. Formou-se, em 1945, na primeira turma de química da então denominada Universidade de Porto Alegre Podemos imaginá-lo, em 1938, guri de 11 anos, mochila de couro nas costas, descendo o Taquari e o Jacui na "gasolina", que é como chamavam os barcos fluviais daquele tempo - ou no barco de rodas à vapor até o cais de Porto Alegre.

Também no ensino colegial O Prof. Dick deixou a sua tnarca. Somando, foram 12 anos de sala de aula, no IPA (1945 a 1948), no Colégio Júlio de Castilhos (1946-1958)quando este ainda se denominava "colégio padrão" e havia tido em seu corpo docente eminentes mestres como o Prof.Alarich Schulz, Abilio Azambuja, Irajá Daniani Pinto e muito outros e ainda, no Colégio de Aplicação da UFRGS (1958 a 1961). 
As organizações e agremiações representativas dos estudantes universitários do Rio Grande do Sul muito devern ao Professor Dick. Em dois anos à testa do Centro Acadêmico Sarmento Leite da Faculdade de Medicina da UFRGS (1952 e 1953) e depois na presidência da FEUPA-FEURGS (1953 e 1954), além da Presidência da Associação dos Exx-alunos do Colégio Sinodal, criou a programação das casas do Estudante Evangélico Universitário de Porte Alegre - hoje com 3 casas em Porto Alegre - e ainda o primeiro Restaurante Universitário no país, administrado exclusivamente por estudantes (FEURGS), na Azenha, em Porto Alegre.

Aqueles que vieram a conhecer o Prof. Dick mais recentemente ou apenas no contexto de sua exitosa atuação nas administrações tegionais ou nacionais, pouco sabem de sua sólida formação científica. Além dos diversos estágios realizados no Brasil, junto à renomados laboratórios de bioquímica e de endocrinologia, bastará lembrar que o pesquisador Dick trabalhou ao lado de três cientistas de renome que mais tarde foram distinguidos com o Prêmio Nobel de Química ou de Medicina, ou seja, Luis Frederico Leloir em 1955, Hans Adolf Krebs em 1956 e 1957 e Feodor Lynen, em 1964 e 1965).

A sua cooperação com o eminente químico Leloir pode ser avaliada pela circunstância de que o único filho homem do Prof. Dick recebeu o mesmo pré-nome - Luis Frederico do consagrado cientista argentino, como relata, orgulhoso, o filho. Sua produção científica, como sabemos, é muito rica e principalmente diversificada, percorrendo os diversos campos da Enzimologia, da Ecotoxicologia e do Monitoramento Ambiental.

Perde-se a conta dos numerosos momentos em que Tuiskon Dick foi destacado e hontado com distinções públicas especiais. Citá-las todas nominalmente por certo romperia os limites de tempo e espaço desta comunicação. Não sei se estaremos acertando a preferência do homenageado, mas a Grã-Cruz da Ordem do Mérito Científico e Tecnológico, do Ministério da Ciência e Tecnologia, recebida das mãos do Presidente da República Fernando Henrique Cardoso na presença do Ministro Ronaldo Sardenberg, no dia 10 de agosto de 2001, em Brasilia, por cetto ocupa um lugar especial nos guardados do ilustre colega.

Não creio que exista algum colegiado da nossa Universidade no qual o Prof. Dick não tenha tido assento, desde às antigas comissões de carteira até o conselho universitário. Passou pela direção do Instituto de Biociências (1972-1976) pela Vice-Reitoria e alcançou o posto de Reitor no período de 1990 a 1992

O período de sua gestão na direção do Instituto de Biociências ccrtamente tem muito a ver com a presença do nosso homenageado no presente seminário. A reforma universitária havia tecétn introduzido profundas altetações na estrututa da universidades, ampliando o espaço dos departamentos e reduzindo as administrações das faculdades e dos institutos a um elenco modesto de atribuições buroctáticas. Muitos diretores entregaram-se ao novo sistema, de forma passiva, quase tesignada, mas não o Diretor Tuiskon Dick. Atento às transformações que se operavam no espaço social, em particular a crescente importância da questão ambiental, tanto no espaço rural como urbano, o Diretor Dick tratou 
de arregimentar os recursos materiais e humanos dos departamentos do Biociências, para qualificar o saber científico e tecnológico necessário para marcar a presença da Universidade no debate em andamento. Completada a etapa da denúncia ambientalista, da mobilização popular para a busca de una relação mais equilibrada com o meio ambiente, faltava ao Brasil a criação de instrumentos de ensino e de pesquisa capazes de preparat os profissionais ecólogos que o país precisava e getar conhecimentos qualificados capazes de instrumentar as decisões públicas e privadas voltadas para a gestão sustentada do meio ambiente. O NIDECO Núcleo Interdepartamental de Estudos Ecológicos - iniciativa de Tuislson Dick, foi absolutamente pioneiro no território brasileiro.

O curso de Especialização em Ecologia, mais tarde transformado em programa sensu stricto, teve como um dos primeiros alunos matriculados o ambientalista José Lutzenberger, o que já é um referencial de acerto da proposta acadêrnica da UFRGS no campo da Ecologia.

O Dr.Paulo Nogueira Neto, à frente da Secretaria do Meio Ambiente do Governo Federal, logo encontrou no NIDECO e depois no subseqüente Centro de Ecologia da UFRGS, ainda sob a direção de Tuiskon Dick, o parceiro ideal para a efetiva implantação das estações ecológicas, Taim e Esmeralda, no sul do país.

A ida de diversos jovens docentes da átea biológica da UFRGS para a Alemanha, na busca de uma formação pós-graduada no campo da Ecologia, foi fortemente estimulada pelo nosso homenageado. Eles representam hoje a base docente do programa de pósgraduação em Ecologia da UFRGS.

No rastro das ações de Dick na diteção do Biociências e do CENECO, construiu-se uma das mais produtivas parcerias já vividas pelo nossa Universidade. O convênio de Cooperação entre a UFRGS e a Universidade de Saarland, na Alemanha, de 1979 a 1987, apoiado com expressivo suporte da SUBIN/SEPLAN, ensejou o apatelhamento técnico e laboratorial do Centro de Ecologia e os trabalhos de pesquisa em desenvolvimento no Estado. A vinda de diversos docentes e pequisadores da Alemanha foi diretamente intermediada por Tuiskon Dick e decisiva para a consolidação da cooperação Brasil/Alemanha no campo da Ecologia.

A ida de Dick para Brasília em 1995, convocado que fora pelo Governo Federal para atuar tanto na Secretaria do Ensino Superior do Ministério da Educação, como na Coordenação da Cooperação Internacional da CAPES/MEC, deu-lhe a grande oportunidade de atender de forma mais ampla e mais intensa as expectativas da conunidade acadêmica brasileira quanto ao intercâtubio e a cooperação universitárias internacionass. A experiència internacional recolhida na UFRGS no campo da Ecologia foi decisiva, quando a CAPES, pelas mãos de seu presidente ABILIO BAETA NEVES e com o apoio de Tuiskon Dick, dinamizou ou construiu os grandes programas cooperativos acadêmicos intemacionais, envolvendo não apenas a Alemanha (UNIBRAL e PROBRAL), mas também a França (COFECUB e BRAFITEC), Portugal (GCCT), Espanha (CAPES/MECD-DGU), Atgentina (SECYT e CEAPG) e os Estados Unidos da América do Norte (CAPES-FIPSE), entre vários outros países. 
A concretização do programa CAPES/FIPSE, terna central do presente conclave e que hoje vive um momento especial de transição e reavaliação, talvez seja um dos tnaiores êxitos da Cooperação Internacional da gestão de Baeta Neves e Tuiskon Dick. Não se deve esquecer que o federalismo exacerbado da grande nação do Norte há anos vinha constituindo um obstáculo para a identificação de uma instância, agência ou repartição de abtangència ou competêtacia amplamente nacional, capaz de dialogar em igualdade de status com a CAPES. A identificação do FIPSE - Fund for the Improvement of Post Secondary Education, do Department of Education, dos Estados Unidos e a consolidação dos laços cooperativos entre as duas agências, foi obra pessoal de Tuiskon Dick e Abilio Baeta Neves e principalmente, uma grande conquista para o Brasil. $A$ formação de parcerias universitárias, voltadas para o intercâmbio de estudantes de graduação nos dois scntidos, a aproximação das estruturas curriculares, prevendo, no futuro, o reconhecimento recíproco de diplomas e a realização de estágios no exterior, são iniciativas de grande valor acadêmico e cultural para formação dos nossos estudantes universitário. De minha parte, tendo participado de diversos momentos gerenciais do acordo CAPES/FIPSE, na seleção e avaliação de projetos de parceria na cidade de Austin, no Texas, em reunião técnica no Departamento de Educação em Washington e ainda, etn reuniões binacionais de seleção de projetos em Brasilia, tive ampla oportunidade de avaliar a importância do programa conn as universidades norte-americanas e convencer-me da necessidade de preservar o acordo e desentvolve-lo ainda mais, com o aporte dos recursos materiais e financeiros necessários.

Ainda restatia dizer algumas palavras sobre o nosso homenageado, enquanto colega, amigo e companheiro de lutas acadêmicas ao longo dos últimos cinqüenta anos.

Em primeiro lugar é preciso falar de sua insuperável afabilidade pessoal, tendo sempre uma palavra ou um gesto atencioso para os amigos e conhecidos. Enquanto alguns visitantes vindos de outras regiões do país ou do exterior eram deixados, por alguns dirigentes, entregues à sua própria sorte na cidade hospedeira, Tuiskon Dick sempre acha uma alternativa para levá-los a um restaurante, um chopinho amigo, um copo de um vinho tinto gaúcho, enfirn, um momento social de hospitalidade. Certamente as suas inumetáveis conquistas junto às autoridades dos mais diversos segmentos da administração publica e privada, se apoiaram na capacidade do Dick de conquistat amigos e mantê-los assim.

Depois, a sua irrestrita fidelidade aos amigos e colaboradotes, aliada à capacidade de delegar competências, sem transferir ou renunciar à sua autoridade. Mas Tuiskon Dick sempre soube também e continua sabendo cobtar dedicação, rapidez e competência de seus colaboradores.

Antes de sua formatuta na Medicina, em 1954, o jovem médico Tuiskon Dick recebeu a incumbência de acompanhar e cuidar da irmã Gudrun, também estudante na Medicina, na viagem dos formandos até Buenos Aires. Foi onde se rendeu aos encantos da Yeda Pinheiro, 
hoje sua esposa, já Professota de Físico-Química da UFRGS. Bem diz o Fruticultor ou o Geneticista - a maça nunca cai longe do pé, pois os três filhos são da área acadêmica: $O$ engenheiro Luis Frederico Pinheiro Dick é docente do CPG Engenharia Metalúrgica/Escola de Engenharia, UFRGS, Deborah Pinheiro Dick está na Química e na Agronomia da UFRGS e Ingrid Dick de Paula, Médica, está na Faculdade de Medicina da USP em Ribeirão Preto.

Assim, pedimos ao Professor Tuiskon Dick que aceite a homenagem que hoje the prestamos, porque diante do que aqui relatamos, reconhecemos na sua pessoa o cientista altamente qualificado, o administrador competente, dedicado e atento às prioridades do espaço social no qual a universidade está inserida, o planejador com ampla visão intetnacional, o estimulador irrestrito das vocações dos jovens para as carreiras universitárias e principalmente, o colega amigo e leal de todas as horas.

Prezado Tuiskon Dick - tem sido uma grande honta e um grande prazer tê-lo ao nosso lado durante todo este tempo. 